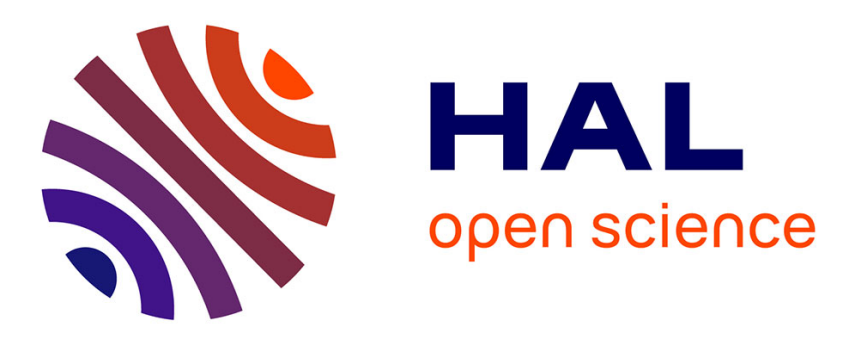

\title{
Design and Evaluation of a Pervasive Workplace Learning System for Retail Stores
}

Yvan Peter, Benjamin Barbry, Thomas Vantroys, Philippe Laporte, Sylvie Lerouge

\section{- To cite this version:}

Yvan Peter, Benjamin Barbry, Thomas Vantroys, Philippe Laporte, Sylvie Lerouge. Design and Evaluation of a Pervasive Workplace Learning System for Retail Stores. 12th International Conference on Advanced Learning Technologies (ICALT), Jul 2012, Rome, Italy. pp.202-204, 10.1109/ICALT.2012.106 . hal-00826329

\section{HAL Id: hal-00826329 \\ https://hal.science/hal-00826329}

Submitted on 4 Jun 2013

HAL is a multi-disciplinary open access archive for the deposit and dissemination of scientific research documents, whether they are published or not. The documents may come from teaching and research institutions in France or abroad, or from public or private research centers.
L'archive ouverte pluridisciplinaire HAL, est destinée au dépôt et à la diffusion de documents scientifiques de niveau recherche, publiés ou non, émanant des établissements d'enseignement et de recherche français ou étrangers, des laboratoires publics ou privés. 


\section{Design and Evaluation of a Pervasive Workplace Learning System for Retail Stores}

\author{
Yvan Peter, Benjamin Barbry, Thomas Vantroys, Philippe Laporte \\ Université Lille 1, LIFL \\ F-59655 Villeneuve d'Ascq \\ France \\ Email: \{name.surname\}@univ-lille1.fr
}

\author{
Sylvie Lerouge \\ Auchan France \\ Institut de Formation à l'Excellence \\ 200, rue de la recherche \\ F-59650 Villeneuve d'Ascq, France \\ Email : slerouge@auchan.com
}

\begin{abstract}
This paper presents the design and evaluation of a system for pervasive learning at the workplace in the domain of the retail industry. The user driven design of the prototypes and the field trials have enabled to put in light the design dimensions of such a solution : resources, activities and environment. We will show in this paper how these dimensions affect the overall solution.
\end{abstract}

Keywords-Pervasive learning, mobile learning, workplace learning

\section{INTRODUCTION}

Companies have to adapt to the evolution of technologies, business processes and competition. Training is an accompanying measure to enhance knowledge and skills of the employees. However, current company training whether face to face or in e-learning has two major drawbacks :

- It is necessary to leave the work activity either to attend a face to face session or to access a computer in a remote place to browse e-learning modules. This creates a break in the work activity;

- The life time of the training resources is not always compatible with the rapid evolution of knowledge and skills necessary to accomplish work activities. This creates a break related to actual workers' training needs.

On the other hand, informal learning occurring through observation and interaction with colleagues provides a learning vector that is equally important [1] and needs equal support from the organisation [2].

Under the p-LearNet research project, we have considered the potential of Weiser's vision of a pervasive world to support integrated learning / working activities [3]:

- the physical environment becomes a learning resource in itself [4] and enables the development of skills and knowledge in real or realistic settings [5]. The context then becomes a crucial element in providing the resources and relevant activities [6], [7];

- The extension of the interaction means within work settings (e.g., mobile devices, tactile surfaces...) offers the capability to access information on the spot but also to produce and disseminate it within the organisation more easily. This opens the possibility to support social and collaborative learning styles [8], [9], [10].
The p-LearNet project involved Auchan, an actor in the retail industry. Auchan had no significant deployment of mobile solutions for their business processes or training. For this reason, we used scenarios as a boot process and involved people in a participatory design process.

This article presents the design and experimentation of the pervasive learning solution. The next section, will cover our experimental setting. We will then outline the features of the prototype before presenting the experimentation phases. An analysis of the benefits and pitfalls identified during the project will conclude the article.

\section{EXPERIMENTAL SETTING}

We were interested in Auchan sellers training. Sellers are at the forefront of the relation with the clients and have multiple roles: seller, counsellor, taking care of the shelves... More and more they are confronted to clients that have already gathered information from the Internet before coming to the store. This is particularly true with the technology products (camera, GPS, television...) that we have considered during the project. Moreover, this type of products have a rapid turnover and change every three months. For their work, the sellers have to integrate information such as the store and brands marketing strategies, distinctive technological features, availability... to best respond to the client's demand.

The brand's training centre offers both face to face and elearning training for business activities and about products. E-learning resources are classical Flash based documents including subject matter information and quiz. To have a better knowledge of the seller population and learning practices, 24 sellers filled in a questionnaire. The average age is 37 years old and most of them (18/24) have more than 5 years experience in the store. Two third of them have been trained for selling either before or after recruitment. Considering their strategies to acquire information, they prefer direct interactions within their department (colleagues and department head). Otherwise, they would rely on product documentation or self experimentation and finally on Internet. Product providers that visit the store to present the new products and their evolution are also a great source of information. The main motivation for learning in this context 
is curiosity, for instance in front of a new product. Most of the sellers have followed at least one e-learning module per year. More than 50 percent of them is satisfied with these modules. However, further research showed that there was a lack for up to date information about new products and that sometimes a seller would arrive in a new department store without any prior training. Above all 92 percent of the sellers identify lack of time as the principal limit to training.

\section{Prototype Proposal}

Starting from initial scenarios and discussions with sellers, training department and other business units, we have decided to concentrate on two scenarios : in situ knowledge revision (seller alone) and selling scaffolding (with a client). For that, the prototype would take the form of a seller digital assistant that would provide access to product information as well as training material (pedagogical resources, F.A.Q., best practices...). To overcome the mobile device limitations (e.g., screen size), the assistant enables the discovery of nearby software and hardware services to include them in a global interaction and activity environment (Figure 1).

The first prototype was developed using Java/Swing on a Samsung Q1 mobile windows PC. The second experiment used a Villiv computer which was a little smaller and lighter and the interface has been redeveloped using Flex to provide a better user experience.

\section{EXPERIMENTATION}

\section{A. Laboratory Experiment}

This experiment involved 8 people from Auchan, 3 from business units and 5 sellers. They had to perform scripts prepared beforehand to drive them to different prototypes functions. Each test was followed by an interview about their feeling about the system and how they foresee its use in a real situation. In addition to bug correction and ergonomic improvements, the experiment showed that we should pay attention to the business context (e.g., organisation of information) and to the impact of introducing a pervasive system in business environment and activities (e.g., position of the screens). Moreover, the relation between the seller and his/her client is changed by the mediation of the system and an adaptation is necessary.

\section{B. Field Experiment}

A first prototype has been deployed for one month within the "nomad" department store (cameras, GPS...) of a local hypermarket, involving 4 sellers. The target products were high-end numeric cameras and GPS devices. Figure 1 shows a typical use of the prototype in store where the seller will select some products based on his discussion with the client. Then, he can share product comparison on an external screen for discussion with the client. The product features can be used as entry points towards resources either on the mobile device for the seller or on the shared screen to

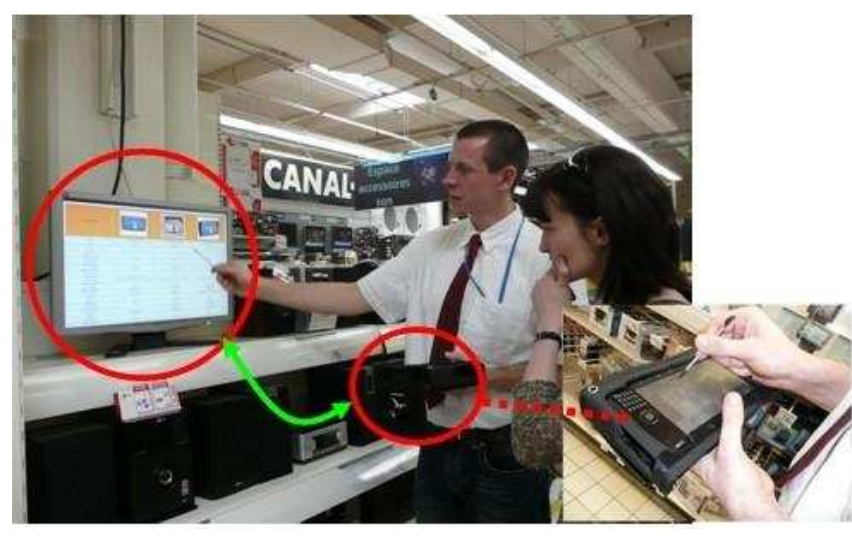

Figure 1. In store: extended interaction with assistant and screen.

the benefit of the client. We have observed that the work environment has a great impact on the deployment of a mobile solution. The organisation of the department store, the capabilities of the mobile device (form factor, autonomy) are important to facilitate the uptake of the solution. The other issue was the availability of pertinent resources. Sellers are very demanding. They need timely product information and market oriented overviews of the product range to support their argumentation in front of the client.

Five vendors were involved in a second experimentation with an updated prototype. They had an interview after the experimentation to get their use and feeling about the prototype. The interview was organised around 4 topics :

- product documentation : the use frequency ranged from scarcely to 5-10 times a week. All the product families covered were concerned (TV, GPS, Photo). The perceived gain was a better and more thorough knowledge of the technical features of the products. Sellers reported using the prototypes alone during dead times but also with other sellers as a support for discussion about products.

- pedagogical resources : two sellers never took a look at the pedagogical resources. Two others had a medium use. One had a regular use. The motivations for using theses resources are the comprehension of some product features, preparing oneself to the arrival of new products and as a support for demonstration with clients.

- use of twitter : twitter integration has been done for the second prototype and experimentation. Two vendors never used the twitter feeds, two used it a few times during the experimentation. The last seller used it 3-4 times a week. They mostly used it alone as a mean to get updates from product provider feeds.

- Prototype features : three sellers still find the prototype too heavy and mention ergonomic issues. Four sellers think that taking control of an external screen is 


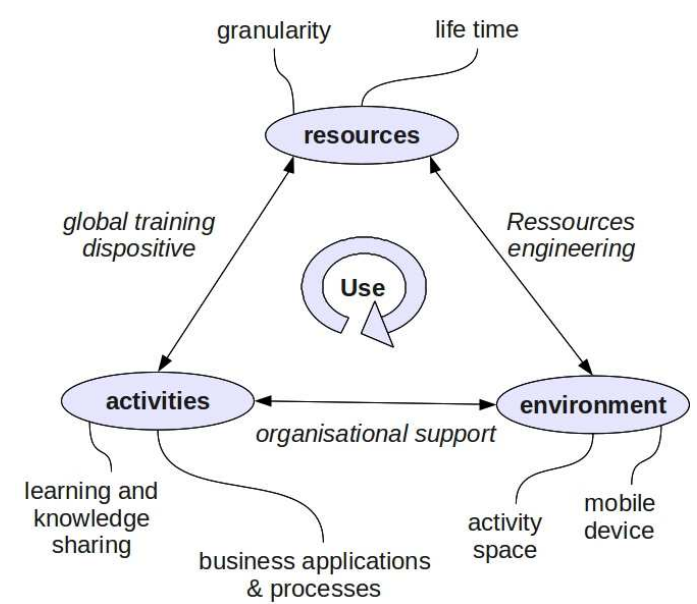

Figure 2. Design elements of pervasive learning.

a good mean to provide information and explanations to the client.

\section{CONCLusion}

During the different phases of the project we have been confronted to the same recurring issues : resources availability, integration of business and training activities and the business environment. The field experiments confirmed the lack of business functions (e.g., stock level, payment services) is a barrier to adoption. The provided resources, while appreciated, raised the interest of the sellers for a very short time. Sellers are very demanding and the resources should have a clear added value regarding their business activities. This added value may be in the help they provide to construct an argumentation in front of the client or as a piece of material they can show to the client. In this respect the Twitter integration we did in our last trial to provide product providers and experts feeds was appreciated because it was very up to date and helped the sellers being aware of market evolution.

Figure 2 shows the different elements and their relations which can be used as a framework for the design of a workplace learning solution :

- resources have to be adapted for mobile use (e.g., granularity) but also to be in line with the evolving needs of the workers;

- learning activities should be strongly associated to the business activities for an easy switch between the two and informal learning modes should be supported;

- the environment including mobile devices should be compatible with the business tasks.

The links between these elements underline three processes that have to be considered for successful deployment of the mobile and pervasive workplace learning:

- mobile and pervasive learning are not a replacement for other learning modes. It is necessary to design a global learning organization including face to face, e-learning and mobile learning modes;

- the engineering process of the resources has to be adapted to fit mobile consumption [11] and to enable quick production according to business evolution;

- the adaptation of the activities and environment for pervasive learning requires an organisational support from different business units and from the local hierarchy to promote learning and knowledge sharing.

Taking these elements into account implies an important evolution of the organisation because of the impact on the business processes and information processing and sharing. It is also crucial for the training departments to be able to stay tuned to the needs of the field users.

\section{ACKNOWLEDGMENT}

This work was partially funded by the French National Research Agency (ANR), p-LearNet project grant.

\section{REFERENCES}

[1] P. Moati, "Les stratégies d'adaptation des entreprises: éléments d'analyse," p. 59, 2001.

[2] S. Billett, "Critiquing workplace learning discourses: participation and continuity at work," Studies in the Education of Adults, vol. 34, no. 1, pp. 56-67, 2002.

[3] M. Weiser, "The computer for the 21st century," Scientific American, 1991.

[4] T. Laine and M. Joy, "Survey on context-aware pervasive learning environments," International Journal of Interactive Mobile Technologies, vol. 3, no. 1, pp. 70-76, 2009.

[5] J. Hundebol and N. H. Helms, "Pervasive e-learning - In situ learning in changing contexts," in Conference on Informal Learning and Digital Media, 2006.

[6] M. Derntl and K. A. Hummel, "Modeling context-aware elearning scenarios," in Pervasive Computing and Communication Workshop (PerCom 2005), 2005, pp. 337-342.

[7] A. Kurti, M. Milrad, F. Alserin, and J. Gustafsson, "Designing and implementing ubiquitous learning activities supported by mobile and positioning technologies," in the Ninth IASTED Conference Computers and Advanced Technology in Education. ACTA Press, 2006.

[8] S. Kaddouci, "Designing learning support for mobile workers," in IEEE International Conference on Advanced Learning Technologies, 2009.

[9] M. Sharples, J. Taylor, and G. Vavoula, A theory of learning for the mobile age. Sage, 2007, pp. 221-247.

[10] E. Wenger, Communities of practice: Learning, meaning, and identity. Cambridge University Press, 1998.

[11] A. F. L. Framework, "M-learning standards review report - version 2.0," Department of Education, Employment and Workplace Relations - Australian Governement, Tech. Rep., October 2008. 